\title{
The Puzzle of the Molecular Identification of Mitochondrial Potassium Channels: Progress in Animals and Impasse in Plants
}

\section{Donato Pastore ${ }^{*}$}

Department of Agricultural, Food and Environmental Sciences, University of Foggia, Italy

In more than 20 years after the discovery of the first mitochondrial potassium channel [1] the scenery is more and more complicated.

In animals, the potassium channels identified by far in the inner mitochondrial membrane include an ATP-inhibited potassium channel $\left(\right.$ mitoK $\left._{\mathrm{ATP}}\right)$, a big and an intermediate conductance calciumactivated potassium channels (BKca and IKca, respectively), a Kv1.3 voltage-gated potassium channel and a TASK-3 two-pore potassium channel; the outer membrane has also been recently shown to possess an inward rectifying potassium channel (Kir). The functional roles of these channels include regulation of mitochondrial matrix volume and apoptosis as well as of mitochondrial respiration and proton motive force. Interestingly, potassium channels may accomplish modulation of reactive oxygen species (ROS) production by mitochondria and in general may have a cytoprotective function. This is of great interest in humans since activation of some potassium channels is believed to protect heart and brain from the ischemic insult $[2,3]$.

In plants, the first mitochondrial potassium channel was shown in 1999 as an ATP-dependent potassium channel $\left(\right.$ PmitoK $\left._{\text {ATP }}\right)$ of durum wheat mitochondria [4]. Recently, it was characterized by patch clamp experiments [5]. Several other mitochondrial potassium channels were described since then in about ten different species. Recently, by using electrophysiological measurements in a reconstituted system, a large conductance mitoBKCa [6], a mitoK ${ }_{\mathrm{ATP}}$ and a large-conductance $\mathrm{Ca}^{2+}$ insensitive and iberiotoxin-sensitive channels were described in potato tuber mitochondria [7]. So, mitochondrial potassium channels are widely present in plants and may have physiological roles similar to that of the animal counterpart. In particular, the original PmitoK ${ }_{\mathrm{ATP}}$ has been shown to act against oxidative stress occurring when plant faces environmental stresses [8-10].

In spite of the great importance in cell physiology, the molecular knowledge proceeds slowly in animals and noway in plants. Only in 2005 the first molecular identification of a mitochondrial potassium channel was achieved thanks to a proper genetic model, in particular that of the mitoKv1.3 in lymphocytes [11]. Interestingly, this channel is the mitochondrial counterpart of a channel normally expressed in plasma membrane. Mironova et al. [12] proposed that also mitoK ${ }_{\text {ATP }}$ may resemble its plasma membrane counterpart; authors proposed the channel to be a hetero-multimeric complex consisting of four $55-\mathrm{kDa}$ inward rectifying $\mathrm{K}^{+}$subunits (mitoKir) and four $63-\mathrm{kDa}$ sulfonylureabinding regulatory subunits (mitoSUR). Accordingly, four years ago the molecular identification and the functional characterization of a sulfonylurea receptor (SUR)2 splice variant generated by intraexonic splicing has been reported in cardiac mitochondria and proposed as a possible component of the mito $_{\text {ATP }}$ channel [13]. The long form of SUR2 is needed for the diazoxide (a channel opener)-sensitive potassium current. The short form of SUR2 has mitochondrial localization and is able to form a glibenclamide (a channel inhibitor)sensitive and ATP-sensitive potassium current on the cell surface with Kir6.1; moreover, by using a genetic approach, it was shown that the short form of SUR2 may contribute to cardioprotection. This has been a first step towards definition of the mitoK $_{\mathrm{ATP}}$ structure, but in that years the main component of the channel, i.e. the pore forming protein, remained elusive. Even, Ardehali et al. [14] showed mitoK ${ }_{\text {ATP }}$ channel activity in a proteoliposome-reconstituted highly purified fraction of the inner mitochondrial membrane lacking Kir or Kv type subunits, but containing five different mitochondrial proteins: mitochondrial ATP-binding cassette protein 1 (mABC1), phosphate carrier, adenine nucleotide translocator, ATP synthase and succinate dehydrogenase. Another paper upset opinions about the pore forming protein. In fact, it was reported that two distinct bands (putative Kir6.1 proteins) of 51 and $48 \mathrm{kDa}$ revealed in isolated heart mitochondria by immunoblots with two commercially available antibodies, after purification were identified by LC-MS/MS as NADH-dehydrogenase flavoprotein 1 and mitochondrial $\mathrm{NADP}^{+}$-dependent isocitrate dehydrogenase, respectively [15]. Consistently, $\mathrm{Ng}$ et al. [16] showed, by means of pharmacological and molecular tools, that Kir6.1 is located in the endoplasmic reticulum and plays a role in modifying $\mathrm{Ca}^{2+}$ release from intracellular store. In particular, cell imaging showed that only little Kir6.1 was distributed in the mitochondria.

At last, the puzzle about the pore forming protein of mitoK $_{\text {ATP }}$ has been solved last year. Foster et al. [17] reported novel and convincing data that identify the renal outer medullary potassium channel (ROMK, Kir1.1) as a subunit of the mitoK ${ }_{\text {ATP }}$ channel in bovine heart mitochondria. In particular, they showed that an isoform of ROMK contains a mitochondrial targeting motif at its $\mathrm{N}$-terminus. Their elegant study combined large-scale unbiased mitochondrial proteomic approach with pharmacological and genetic manipulation. They showed that the honeybee venom toxin tertiapin-Q, a highaffinity ROMK toxin, as well as ROMK knockdown inhibits mitoK ${ }_{\text {ATP }}$ activity. Moreover, the overexpression of ROMK protects against cardiomyoblast death, while ROMK knockdown increases cell death, thus assessing the role of ROMK in cardioprotection. Finally, they showed by RT-PCR that ROMK isoforms are present not only in heart (neonatal rat ventricular myocytes and adult rat hearts), but also in brain and liver, thus suggesting possible molecular assessment in other different organs, all having mitoK $_{\mathrm{ATP}}$ activity. The identification of mitoROMK in heart provides an important molecular target for mechanistic and therapeutic investigation against ischemia-reperfusion injury and represents such advancement in the knowledge in this field that Rines et al [18] emphatically entitled a recent editorial about this topic: "A new pROM king for the mitoK $_{\text {ATP }}$ dance ROMK takes the lead".

*Corresponding author: Donato Pastore, Department of Agricultural, Food and Environmental Sciences, University of Foggia Via Napoli, 25-71122 Foggia, Italy, Tel: 39(0)881589427/32; Fax: 39(0)881587108; E-mail: d.pastore@unifg.it

Received November 25, 2013; Accepted November 27, 2013; Published November 29, 2013

Citation: Pastore D (2013) The Puzzle of the Molecular Identification of Mitochondrial Potassium Channels: Progress in Animals and Impasse in Plants. Bioenergetics 2: e118. doi:10.4172/2167-7662.1000e118

Copyright: $\odot 2013$ Pastore D. This is an open-access article distributed under the terms of the Creative Commons Attribution License, which permits unrestricted use, distribution, and reproduction in any medium, provided the original author and source are credited. 
This exciting escalation of knowledge about mitochondrial potassium channels concerned also another kind of channel, the mitoBKca. The BKca, encoded by the Kcnma 1 gene, is generally expressed at the plasma membrane of excitable and non excitable cells. On the other hand, in adult cardiomyocytes a BKca-like channel activity has been reported in the mitochondria and not at the plasma membrane, but so far the molecular origin of this mitoBKca was unknown. This year, it has been shown that in cardiomyocytes mitoBKca is also encoded by the Kcnma 1 gene, and a splicing sequence defines its mitochondrial location [19]. Anyway, it should be also reported that adopting Caenorhabditis elegans and mouse genetic models, the canonical BKca channel coded from SLO1 (Kcnma 1) gene proved to be dispensable for both mitochondrial potassium transport and anesthetic preconditioning (a process acting against ischemic injury), while the related, but physiologically-distinct potassium channel SLO-2 is cytoprotective and contributes to mitochondrial potassium transport [20].

Within this complex framework, what about plant mitochondrial potassium channel at molecular level? Little or nothing. At my best knowledge only an abstract is available about the partial purification of a potato mitoK ${ }_{\text {ATP }}$, suggested to contain Kir and SUR type subunits [21] and the recognition of a $\beta$ regulatory subunit of a non-identified voltage gated potassium channel obtained by a proteomic approach in rice mitochondria [22]. Apart from this few information, we have only some hypotheses based on gene sequence homology and biochemical and pharmacological properties of the channels $[5,9]$. The components of the PmitoK $\mathrm{K}_{\text {ATP }}$ and other mitochondrial potassium channel have remained elusive since their initial discovery, as investigation into their composition has been hindered by the low abundance of potassium channels in mitochondria and by some lack of pharmacological specificity. How to resolve the impasse? Patch clamp in swollen mitoplasts, i.e. in the inner membrane, directly proves the presence and the characteristics of a potassium channel in that membrane, but plant mitochondria are difficult to be analysed by this technique and so far only one paper reported a limited electrophysiological analysis [5]. Immunoreactivity or colocalization/imaging studies will be useful, on the other hand studies only based on these techniques hardly may be considered conclusive. As taught by the experience in animals, the best way to study gene/protein relationship in plant mitochondrial potassium channels will be the proteomic analysis combined with a genetic (and RNA interference) approach. Just now, the molecular identities of plant channels remain largely enigmatic.

\section{References}

1. Inoue I, Nagase $\mathrm{H}$, Kishi K, Higuti T (1991) ATP-sensitive $\mathrm{K}^{+}$channel in the mitochondrial inner membrane. Nature 352: 244-247.

2. Szabò I, Leanza L, Gulbins E, Zoratti M (2012) Physiology of potassium channels in the inner membrane of mitochondria. Pflugers Arch 463: 231-246.

3. Szewczyk A, Jarmuszkiewicz W, Kunz WS (2009) Mitochondrial potassium channels. IUBMB Life 61: 134-143.

4. Pastore D, Stoppelli MC, Di Fonzo N, Passarella S (1999) The existence of the $\mathrm{K}^{+}$channel in plant mitochondria. J Biol Chem 274: 26683-26690.
5. De Marchi U, Checchetto V, Zanetti M, Teardo E Soccio M et al (2010) ATP sensitive cation-channel in wheat (Triticum durum Desf.): identification and characterization of a plant mitochondrial channel by patch-clamp. Cell Physiol Biochem 26: 975-982.

6. Koszela-Piotrowska I, Matkovic K, Szewczyk A, Jarmuszkiewicz W (2009) A large-conductance calcium-activated potassium channel in potato (Solanum tuberosum) tuber mitochondria. Biochem J 424: 307-316.

7. Matkovic K, Koszela-Piotrowska I, Jarmuszkiewicz W, Szewczyk A (2011) Ion conductance pathways in potato tuber (Solanum tuberosum) inner mitochondrial membrane. Biochim Biophys Acta 1807: 275-285.

8. Pastore D, Trono D, Laus MN, Di Fonzo N, Flagella Z (2007) Possible plant mitochondria involvement in cell adaptation to drought stress. A case study: durum wheat mitochondria. J Exp Bot 58: 195-210.

9. Pastore D, Laus MN, Soccio M (2010) Plant mitochondrial potassium channe or channels? In Mitochondria: Structure, Function and Dysfunction (ed. O.L. Svensson). Nova Science Publishers Inc, New York, USA.

10. Jarmuszkiewicz W, Matkovic K, Koszela-Piotrowska I (2010) Potassium channels in the mitochondria of unicellular eukaryotes and plants. FEBS Lett 584: 2057-2062

11. Szabò I, Bock J, Jekle A, Soddemann M, Adams C, et al. (2005) A nove potassium channel in lymphocyte mitochondria. J Biol Chem 280: 1279012798.

12. Mironova GD, Negoda AE, Marinov BS, Paucek P, Costa AD, et al. (2004) Functional distinctions between the mitochondrial ATP-dependent $\mathrm{K}^{+}$channe ( mitoK $_{\text {ATP }}$ ) and its inward rectifier subunit (mitoKIR). J Biol Chem 279: 3256232568 .

13. Ye B, Kroboth L, Pu JL, Sims JJ, Aggarwal NT, et al (2009) Molecular identification and functional characterization of a mitochondrial sulfonylurea receptor 2 splice variant generated by intraexonic splicing. Circ Res 105: 10831093.

14. Ardehali H, Chen Z, Ko Y, Mejia-Alvarez R, Marbán E (2004) Multiprotein complex containing succinate dehydrogenase confers mitochondrial ATPsensitive $\mathrm{K}^{+}$channel activity. Proc Natl Acad Sci USA 101: 11880-11885.

15. Foster DB, Rucker JJ, Marbán E, (2008) Is Kir6.1 a subunit of mitoK ${ }_{\text {ATP }}$ ? Biochem Biophys Res Commun 366: 649-656.

16. Ng KE, Schawarzer S, Duchen MR, Tinker A (2010) The intracellular localization and function of the ATP-sensitive $\mathrm{K}^{+}$channel subunit Kir6.1. J Membrane Biol 234: $137-147$.

17. Foster DB, Ho AS, Garlid AO, Chen L, Sidor A, et al. (2012) Mitochondria ROMK channel is a molecular component of mitoK $_{A T P}$. Circ Res 111: 446-454.

18. Rines AK, Bayeva M, Ardehali $H$ (2012) A new pROM king for the mitoK ${ }_{\text {ATP }}$ dance ROMK takes the lead. Circ Res 111: 392-393.

19. Singh H, Lu R, Bopassa JC, Meredith AL, Stefani E, et al. (2013) mitoBKca is encoded by the Kcnma1 gene, and a splicing sequence defines its mitochondrial location. Proc Natl Acad Sci USA 110: 10836-10841.

20. Wojtovich AP, Sherman TA, Nadtochiy SM, Urciuoli WR, Brookes PS, et al. (2011) SLO-2 is cytoprotective and contributes to mitochondrial potassium transport. Plos One 6: 28287.

21. Paucek P, Dolgacova L, Garlid KD (2002) Purification and reconstitution of KATP channel $\left(\right.$ pmitoK $_{\text {ATP }}$ ) of plant mitochondria. Biophys J 82: 109.

22. Tanaka N, Fujita M, Handa H, Murayama S, Uemura M, et al. (2004) Proteomics of the rice cell: systematic identification of the protein populations in subcellular compartments. Mol Genet Genomics 271:566-576. 